\title{
IMPACTO DA INOVAÇÃO TECNOLÓGICA NAS INDÚSTRIAS SITUADAS NO BRASIL
}

\author{
Carlos Eduardo de Oliveira ${ }^{1}$ \\ Universidade Federal de Uberlândia \\ carlos.oliveira@ufu.br \\ Ana Paula Macedo de Avellar ${ }^{2}$ \\ Universidade Federal de Uberlândia \\ anaavellar@ufu.br
}

\begin{abstract}
Resumo
Este estudo teve como objetivo verificar o impacto da inovação tecnológica (produto e processo) realizada pelas empresas situadas no Brasil, "no produto" e "no processo". Realizou-se a caracterização das empresas com base em quatro conjuntos de indicadores de impacto (produto e processo), da Pesquisa de Inovação (PINTEC). Efetuouse separação das empresas por tipo de inovação realizada, formando-se grupos: empresas que realizaram "somente inovação de produto", "somente inovação de processo" e "inovação de produto e processo" concomitantemente. Os principais resultados mostraram a preferência das empresas em realizar mais de um tipo de inovação simultaneamente ("produto e processo"), por apresentar quantidade de empresas significativamente superior ao das empresas que realizaram "somente inovação de produto" e "somente inovação de processo"; o impacto da inovação se deu principalmente "no produto", e, em relação ao impacto "no processo", destaca-se o "aumento da flexibilização da produção" e o "aumento da capacidade produtiva".
\end{abstract}

Palavras-chave: Inovação. Inovação tecnológica. Impactos da inovação.

\section{IMPACT OF TECHNOLOGICAL INNOVATION ON INDUSTRIES LOCATED IN BRAZIL}

\begin{abstract}
This study aimed to determine the impact of technologic innovation (product and process) made by firms located in Brazil, "in product", and "in process". There was the characterization of the companies based on four sets of impact indicators (product and process), in Innovation Research (PINTEC). It conducted separation of enterprises by type of innovation performed, forming groups: companies that made "only product innovation", "only process innovation" and "product innovation and process" concurrently. The main results showed the preference of companies to make more than one type of innovation simultaneously ("product and process"), due to its amount significantly higher companies to the companies that made "only product innovation" and "only innovation process"; the impact of innovation was mainly "in product", and about the impact "in process", highlight the "increased flexibility of production" and the "increase in production capacity".
\end{abstract}

Keywords: Innovation. Technologic innovation. Innovation impacts.

1 Doutor em Economia (IE/UFU). Mestre em Engenharia de Produção (FEB/UNESP). MBA em Gestão Empresarial com Ênfase em Finanças (FECAP). Graduado em Ciências Contábeis (ITE). Docente Efetivo da FACES/UFU.

${ }^{2}$ Docente Efetiva do Instituto de Economia da Universidade Federal de Uberlândia (IE/UFU).

(C) (\$) Esta obra está licenciada sob uma licença

(c) BY SA Creative Commons Attribution 4.0 International (CC BY-NC-SA 4.0). P2P \& INOVAÇÃO, Rio de Janeiro, v. 7, n. 1, p. 260-274, set. 2020/fev. 2021. 


\section{ARTIGO}

INOVAÇÃO

\section{INTRODUÇÃO}

Em um ambiente empresarial globalizado, onde a concorrência entre empresas e produtos é acirrada, as empresas devem buscar alternativas para a diferenciação nesse mercado competitivo. O capitalismo é, por natureza, uma forma ou método de transformação econômica (SCHUMPETER, 1961); ao tratar do capitalismo, trata-se também de um processo evolutivo; a vida econômica transcorre em um meio natural e social que se modifica, alterando sua situação econômica.

As revoluções industriais ocorridas, bem como as tecnológicas, favoreceram o surgimento de novos produtos, processos e formas de organização de forma incessante, o que Schumpeter (1961) chama de mutação industrial, provocando alterações na estrutura econômica a partir de dentro, destruindo incessantemente o antigo e criando elementos novos, e é esse processo de "destruição criadora" que serve para entender o capitalismo, e como as empresas devem se adaptar para sobreviver.

A principal razão para mudanças no ritmo de crescimento econômico é o comportamento empreendedor na forma de inovação. O empreendedor é um inovador que combina de forma eficiente os recursos, adota novas melhorias técnicas em máquinas e organiza de forma mais eficiente a divisão do trabalho (SCHUMPETER, 1982).

As inovações referem-se essencialmente à procura, à descoberta, à experimentação, ao desenvolvimento, à imitação e à adoção de novos produtos, processos e formas de organização (DOSI, 1988). A inovação pode ser definida como um novo produto, serviço, processo de produção, estrutura, sistema administrativo, plano ou programa adotado pela organização (DAMANPOUR, 1991).

O progresso técnico, tanto na forma de inovações de processo como na forma de inovações de produto, pode ser considerado um fator de criação de assimetrias, que tendem a induzir uma divergência entre empresas e entre países, em termos de especialização internacional (DOSI, 2006).

No caso de aumento de produtividade das inovações de processo, a empresa obtém uma vantagem de custo sobre seus concorrentes, enquanto no caso de inovações de produto, a empresa pode entrar em uma posição de monopólio ou oligopólio (SCHUMPETER, 1982).

Considerando-se a importância da inovação, este estudo tem como objetivo verificar o impacto das inovações de produto e processo nas indústrias situadas no Brasil. Foram verificados os impactos da inovação em produto e processo, com base em um conjunto de 


\section{ARTIGO}

INOVAÇÃo

indicadores de impacto utilizados pela Pesquisa de Inovação (PINTEC), edições de 2008 e 2011, realizadas pelo Instituto Brasileiro de Geografia e Estatística (IBGE).

Este estudo está estruturado em cinco seções. A primeira seção é composta desta introdução; a segunda seção apresenta o referencial teórico, composta por considerações sobre os aspectos conceituais da inovação. A terceira seção apresenta os procedimentos metodológicos; a quarta seção é composta dos resultados do estudo e, por fim, a quinta seção apresenta as considerações finais.

\section{ASPECTOS CONCEITUAIS ACERCA DA INOVAÇÃO}

Apresentam-se alguns aspectos conceituais acerca da inovação, não com a intenção de esgotar o assunto, mas com o intuito de clarificar ao leitor alguns de seus aspectos relevantes, de acordo com a literatura nacional e internacional. De acordo com o Manual de Oslo, uma inovação pode ser entendida como a implementação de um produto (bem ou serviço) novo ou significativamente melhorado, ou um processo, ou um novo método de marketing, ou um novo método organizacional nas práticas de negócios, na organização do local de trabalho ou nas relações externas (OCDE, 2005). O Quadro 1 apresenta algumas definições de inovação.

Quadro 1 - Algumas definições de inovação.

\begin{tabular}{|c|c|}
\hline Autor & Definição \\
\hline Schumpeter (1934) & $\begin{array}{l}\text { Introdução de novo bem ou qualidade de um bem, introdução de novo método de } \\
\text { produção, abertura de novo mercado, conquista de nova fonte de abastecimento de } \\
\text { matérias-primas, realização da nova organização de qualquer indústria. }\end{array}$ \\
\hline Knight (1967) & $\begin{array}{l}\text { Adoção de uma mudança que é nova para a organização e relevante para o meio } \\
\text { ambiente. }\end{array}$ \\
\hline Thompson (1965) & Geração, aceitação e implementação de novas ideias, processos, produtos ou serviços. \\
\hline $\begin{array}{l}\text { Becker e } \\
\text { Whisler (1967) }\end{array}$ & $\begin{array}{l}\text { Primeira utilização ou início de uma ideia por um conjunto de organizações com } \\
\text { objetivos semelhantes. }\end{array}$ \\
\hline $\begin{array}{l}\text { Downs e } \\
\text { Mohr (1976) }\end{array}$ & Adoção de meios ou fins que são novos para a unidade de adoção. \\
\hline $\begin{array}{l}\text { Tushman e } \\
\text { Nadler (1986) }\end{array}$ & $\begin{array}{l}\text { A inovação é a criação de qualquer produto, serviço ou processo que é novo para uma } \\
\text { unidade de negócios. }\end{array}$ \\
\hline Damanpour (1996) & $\begin{array}{l}\text { Meio de mudança de uma organização, como resposta a alteraçães no ambiente } \\
\text { externo, ou ação preventiva para influenciar o ambiente. A inovação é amplamente } \\
\text { definida para abranger uma gama de tipos, como novo produto ou serviço, nova } \\
\text { tecnologia de processo, nova estrutura de organização ou sistemas administrativos, } \\
\text { ou novos planos ou programas relativos a membros da organização. }\end{array}$ \\
\hline $\begin{array}{l}\text { West e } \\
\text { Anderson (1996) }\end{array}$ & $\begin{array}{l}\text { A aplicação efetiva de processos e produtos novos para a organização e destinados a } \\
\text { beneficiá-la e seus stakeholders. }\end{array}$ \\
\hline Baumol (2002) & $\begin{array}{l}\text { O reconhecimento de oportunidades de mudança rentável e a busca dessas } \\
\text { oportunidades por todo o caminho até à sua adoção na prática. }\end{array}$ \\
\hline $\begin{array}{l}\text { Chen; } \\
\text { Zhaohui e } \\
\text { Xie (2004) }\end{array}$ & $\begin{array}{l}\text { A introdução de uma nova combinação dos fatores essenciais de produção no sistema } \\
\text { de produção. }\end{array}$ \\
\hline
\end{tabular}




\begin{tabular}{|l|l|}
\hline Plessis (2007) & $\begin{array}{l}\text { Criação de novos conhecimentos e ideias para trazer novos resultados de negócios, } \\
\text { visando a melhoria dos processos internos, e criar mercado impulsionando produtos } \\
\text { e serviços. }\end{array}$ \\
\hline $\begin{array}{l}\text { Garcia-Morales; } \\
\text { Matias-Reche e } \\
\text { Hurtado-Torres (2008) }\end{array}$ & $\begin{array}{l}\text { Nova ideia, método ou dispositivo; ato de criação de um novo produto ou processo, } \\
\text { que inclui invenção, bem como o trabalho necessário para trazer uma ideia ou } \\
\text { conceito em sua forma final. }\end{array}$ \\
\hline $\begin{array}{l}\text { Baregheh; } \\
\text { Rowley e } \\
\text { Sambrook (2009) }\end{array}$ & $\begin{array}{l}\text { O processo de vários estágios em que as organizações transformam ideias em novos } \\
\text { e melhores produtos, serviços ou processos, a fim de avançar, competir e diferenciar- } \\
\text { se com sucesso em seu mercado. }\end{array}$ \\
\hline
\end{tabular}

Fonte: Adaptado de Ariss e Deilami, 2012.

O requisito mínimo para se definir uma inovação é que o produto, o processo, o método de marketing ou organizacional sejam novos (ou significativamente melhorados) para a empresa (OCDE, 2005). Para que uma inovação seja considerada como tal, ela deve ter sido implementada pela empresa. Uma inovação pode consistir na implementação de uma única mudança significativa, ou em uma série de pequenas mudanças incrementais que podem, juntas, constituir uma mudança significativa (OCDE, 2005).

Uma empresa inovadora é aquela que implementou uma inovação durante o período de análise e as atividades de inovação são etapas científicas, tecnológicas, organizacionais, financeiras e comerciais que conduzem, ou visam conduzir, à implementação de inovações (OCDE, 2005). As inovações implementadas devem gerar no sistema econômico eficiência produtiva, com ganhos de produtividade criando vantagens relativas ou absolutas de custos (ou produtos) aumentando a competitividade no mercado (ABDI, [2014?]).

Quadro 2 - Tipos de inovações.

\begin{tabular}{|l|l|}
\hline \multicolumn{1}{|c|}{ Tipos de inovações } & \multicolumn{1}{c|}{ Descrição } \\
\hline Inovações de produto & $\begin{array}{l}\text { Envolvem mudanças significativas nas potencialidades de produtos e serviços. } \\
\text { Incluem-se bens e serviços totalmente novos e aperfeiçoamentos importantes para } \\
\text { produtos existentes. }\end{array}$ \\
\hline Inovações de processo & Representam mudanças significativas nos métodos de produção e de distribuição. \\
\hline $\begin{array}{l}\text { Inovações } \\
\text { organizacionais }\end{array}$ & $\begin{array}{l}\text { Referem-se à implementação de novos métodos organizacionais, tais como } \\
\text { mudanças em práticas de negócios, na organização do local de trabalho ou nas } \\
\text { relações externas da empresa. }\end{array}$ \\
\hline Inovações de marketing & $\begin{array}{l}\text { Envolvem a implementação de novos métodos de marketing, incluindo mudanças no } \\
\text { design do produto e na embalagem, na promoção do produto e sua colocação, e em } \\
\text { métodos de estabelecimento de preços de bens e de serviços. }\end{array}$ \\
\hline
\end{tabular}

Fonte: Adaptado de OCDE, 2005.

Uma importante distinção refere-se aos tipos de inovação. O Manual de Oslo (OCDE, 2005) define quatro tipos de inovações que encerram um amplo conjunto de mudanças nas atividades das empresas: (i) inovações de produto, (ii) inovações de processo, (iii) inovações 
organizacionais e (iv) inovações de marketing. O Quadro 2 apresenta os quatro tipos de inovações definidos por este manual.

Evangelista e Vezzani (2010) identificaram quatro modos de inovação distintos, com base no tipo específico de inovação introduzida por empresas de manufatura e serviços, e nas formas em que as empresas combinam inovações tecnológicas e não tecnológicas: dois desses modos de inovação são caracterizados por produto e processo; um terceiro baseia-se na introdução de inovações organizacionais e um quarto é caracterizado por uma mistura mais complexa de produtos, processos e mudanças organizacionais.

Algumas inovações possuem características que aparecem em mais de um tipo de inovação, tornando-se complexa sua categorização. Para orientar a classificação de uma inovação entre os tipos considerados (produto, processo, organizacional e marketing), apresentam-se no Quadro 3, as diretrizes para a distinção entre os diversos tipos de inovação, de acordo com o Manual de Oslo (OCDE, 2005).

Quadro 3 - Diretrizes para a distinção entre os tipos de inovação.

\begin{tabular}{|c|c|}
\hline $\begin{array}{l}\text { Distinção entre } \\
\text { inovação de: }\end{array}$ & Diretrizes \\
\hline $\begin{array}{l}\text { Produto e } \\
\text { Processo }\end{array}$ & $\begin{array}{l}\text { - Se a inovação envolve características novas ou substancialmente melhoradas do serviço } \\
\text { oferecido aos consumidores, trate-se de uma inovação de produto; } \\
\text { - Se a inovação envolve métodos, equipamentos e/ou habilidades para o desempenho do } \\
\text { serviço, novos ou substancialmente melhorados, então é uma inovação de processo; } \\
\text { - Se a inovação envolve melhorias substanciais nas características do serviço oferecido e } \\
\text { nos métodos, equipamentos e/ou habilidades usados para seu desempenho, ela é uma } \\
\text { inovação tanto de produto como de processo. }\end{array}$ \\
\hline $\begin{array}{l}\text { Produto e de } \\
\text { Marketing }\end{array}$ & $\begin{array}{l}\text { O principal fator diferenciador é uma mudança significativa nas funções ou nos usos do } \\
\text { produto. Os bens ou serviços que possuem características funcionais ou de uso } \\
\text { significativamente melhoradas, em comparação aos produtos existentes, são inovações de } \\
\text { produto. Por um lado, a adoção de um novo conceito de marketing, que envolve uma } \\
\text { mudança substancial no design de um produto existente, é uma inovação de marketing, mas } \\
\text { não uma inovação de produto, à medida que as características funcionais ou de uso do } \\
\text { produto não mudaram significativamente. Em alguns casos, as inovações podem ser } \\
\text { consideradas de produto e de marketing, se as empresas implementam alterações em } \\
\text { produtos existentes que envolvem tanto mudanças significativas nas funções ou no uso do } \\
\text { produto, como mudanças significativas na forma e na aparência ou na embalagem do } \\
\text { produto, constituindo um novo conceito de marketing. }\end{array}$ \\
\hline $\begin{array}{l}\text { Serviços } \\
\text { (produto) e de } \\
\text { Marketing }\end{array}$ & $\begin{array}{l}\text { O principal fator que diferencia as inovações de serviços das inovações de marketing é se a } \\
\text { inovação envolve um método de marketing ou um serviço (isto é, um produto). As empresas } \\
\text { serão geralmente capazes de distinguir entre seus métodos de vendas/marketing e seus } \\
\text { produtos. Essa distinção pode depender da natureza dos negócios da empresa. Algumas } \\
\text { inovações são simultaneamente de produto e de processo, como quando uma empresa } \\
\text { implementa uma nova operação de vendas ou de serviços ao consumidor, introduzindo um } \\
\text { novo método de marketing para seus produtos (vendas diretas), ao mesmo tempo em que } \\
\text { oferece aos consumidores serviços adicionais (por exemplo, de reparação) e informações } \\
\text { sobre seus produtos. }\end{array}$ \\
\hline $\begin{array}{l}\text { Processo e de } \\
\text { Marketing }\end{array}$ & $\begin{array}{l}\text { As inovações de processo referem-se a métodos de produção e de distribuição e a outras } \\
\text { atividades auxiliares de suporte, visando a redução dos custos unitários ou o aumento da } \\
\text { qualidade do produto, enquanto as inovações de marketing objetivam o aumento do volume }\end{array}$ \\
\hline
\end{tabular}




\begin{tabular}{|l|l|}
\hline & $\begin{array}{l}\text { das vendas ou da fatia de mercado, por meio de mudanças no posicionamento do produto e } \\
\text { na sua reputação. }\end{array}$ \\
\hline $\begin{array}{l}\text { Este é o caso mais frequente em pesquisas sobre inovação, pois ambos os tipos de inovação } \\
\text { procuram, entre outras coisas, reduzir custos por meio de conceitos novos e mais eficientes } \\
\text { de produção, distribuição e organização interna. Muitas inovações contêm aspectos dos dois } \\
\text { tipos. O ponto de partida para diferenciar inovações de processo e/ou organizacionais é o } \\
\text { tipo de atividade: inovações de processo lidam, sobretudo, com a implementação de novos } \\
\text { equipamentos, softwares, técnicas ou procedimentos, enquanto as inovações organizacionais } \\
\text { lidam primordialmente com pessoas e a organização do trabalho. As diretrizes para } \\
\text { distinguir os dois tipos em casos de fronteira são as seguintes: } \\
- \text { Se a inovação envolve métodos de produção ou de abastecimento novos ou } \\
\text { significativamente melhorados, que visam reduzir custos unitários ou aumentar a qualidade } \\
\text { do produto, trata-se de uma inovação de processo; } \\
\text { - Se a inovação compreende o primeiro uso de novos métodos organizacionais nas práticas } \\
\text { de negócios, na organização do local de trabalho ou nas relaçães externas da empresa, ela é } \\
\text { uma IO; } \\
\text { - Se a inovação implica em métodos de produção ou de abastecimento novos ou } \\
\text { significativamente melhorados, tem-se uma inovação de processo e organizacional. }\end{array}$ \\
\hline Marketing e & $\begin{array}{l}\text { Casos de fronteira podem surgir para inovações que envolvem a introdução de métodos de } \\
\text { marketing e organizacionais. Se uma inovação possui características dos dois tipos, ela é } \\
\text { uma inovação tanto de marketing quanto organizacional. Contudo, inovações } \\
\text { Organizacionais, que envolvem atividades de vendas (por exemplo, a integração dos } \\
\text { departamentos de vendas com outros departamentos), mas não envolvem a introdução de } \\
\text { novos métodos de marketing, não são inovações de marketing. }\end{array}$ \\
\hline
\end{tabular}

Fonte: Adaptado de OCDE, 2005.

A distinção entre os tipos de inovação é complexa e estas diretrizes contribuem para minimizar possíveis dúvidas sobre como classificar uma determinada inovação. Outro tipo de classificação existente na literatura, porém não enfatizada no presente estudo, classifica as inovações de acordo com o seu grau de novidade, ou ruptura, como incremental e radical (FREEMAN, 1974); incremental, modular, arquitetural e radical (HENDERSON; CLARK, 1990); sustentadora e disruptiva (CHRISTENSEN, 1997) e incremental, really new e radical (GARCIA; CALANTONE, 2001).

Contudo, as inovações compreendem amplo espectro de ganhos de eficiência produtiva, decorrentes de inovações incrementais simples, que geram melhorias práticas na organização de tarefas na produção, e de inovações radicais, que mudam os parâmetros de produção e criam produtos e processos genuinamente diferentes para o mercado (ABDI, [2014?]). Considera-se, então, a importância das inovações para a sustentabilidade das empresas.

\section{NOTAS METODOLÓGICAS}

Foi obtido junto ao IBGE, Tabulação Especial dos dados das duas últimas edições da PINTEC (IBGE, 2008; 2011). Inicialmente, as empresas foram divididas em grupos, de acordo com o tipo de inovação realizada, conforme o Quadro 4. 
Quadro 4 - Agrupamento de empresas que realizaram inovações.

\begin{tabular}{|l|l|}
\hline \multicolumn{1}{|c|}{ Descrição } & \multicolumn{1}{c|}{ Características } \\
\hline Inovadoras & $\begin{array}{l}\text { Empresas inovadoras. Referem-se às “empresas que implementaram produto } \\
\text { e/ou processo novo ou substancialmente aprimorado, que desenvolveram } \\
\text { projetos que foram abandonados ou ficaram incompletos, e que realizaram } \\
\text { inovações organizacionais e/ou de marketing. }\end{array}$ \\
\hline Somente Inovação de Produto & Empresas que realizaram somente inovações de produto. \\
\hline Somente Inovação de Processo & Empresas que realizaram somente inovações de processo. \\
\hline $\begin{array}{l}\text { Inovações de Produto e/ou } \\
\text { Processo (IT) }\end{array}$ & Empresas que realizaram inovações de produto e/ou inovações de processo. \\
\hline
\end{tabular}

Fonte: Elaborado pelo autor.

Foi realizada uma caracterização das empresas analisadas, com base em um conjunto de indicadores de impacto apresentados pela PINTEC. Realizou-se a análise dos impactos causados pela inovação nos grupos de empresas selecionados, por grau de importância (alta ou média, baixa ou não relevante). Para cada um dos grupos de empresas, foram analisadas as variáveis apresentadas no Quadro 5.

Quadro 5 - Lista de impactos das inovações.

\begin{tabular}{|c|c|c|}
\hline Impactos & Tipo de impacto & Descrição \\
\hline \multirow{2}{*}{ No Produto } & Melhoria da qualidade dos produtos & \multirow{9}{*}{$\begin{array}{l}\text { Quantidade de empresas } \\
\text { que assinalaram como "Alta } \\
\text { ou Média", "Baixa ou Não } \\
\text { Relevante", o grau de } \\
\text { importância em cada um } \\
\text { destes itens. }\end{array}$} \\
\hline & Ampliação da gama de produtos ofertados & \\
\hline \multirow{7}{*}{ No Processo } & Aumento da capacidade produtiva & \\
\hline & Aumento da flexibilidade da produção & \\
\hline & Redução dos custos de produção & \\
\hline & Redução dos custos do trabalho & \\
\hline & Redução do consumo de matéria-prima & \\
\hline & Redução do consumo de energia & \\
\hline & Redução do consumo de água & \\
\hline
\end{tabular}

Fonte: Adaptado do questionário da PINTEC edição de 2011 (IBGE, 2011).

Em relação aos indicadores de impacto, o questionário da PINTEC solicita ao respondente, entre outros, o grau de impacto em relação à inovação de produto e ou processo realizada, portanto, não captando outros tipos de inovação. São utilizados dados da Tabulação Especial da PINTEC de 2008 e 2011, portanto, tomados em determinado ponto no tempo. A próxima seção apresenta os resultados do estudo.

\section{RESULTADOS DO ESTUDO}

Apresenta-se inicialmente, a quantidade de empresas que realizaram inovações no período analisado, bem como por tipo de inovação, ou seja, se a inovação realizada foi somente 
de produto, somente de processo, como também inovação tecnológica (produto e processo), de acordo com o Gráfico 1.

Gráfico 1 - Total de empresas que realizaram inovações por tipo de inovação.

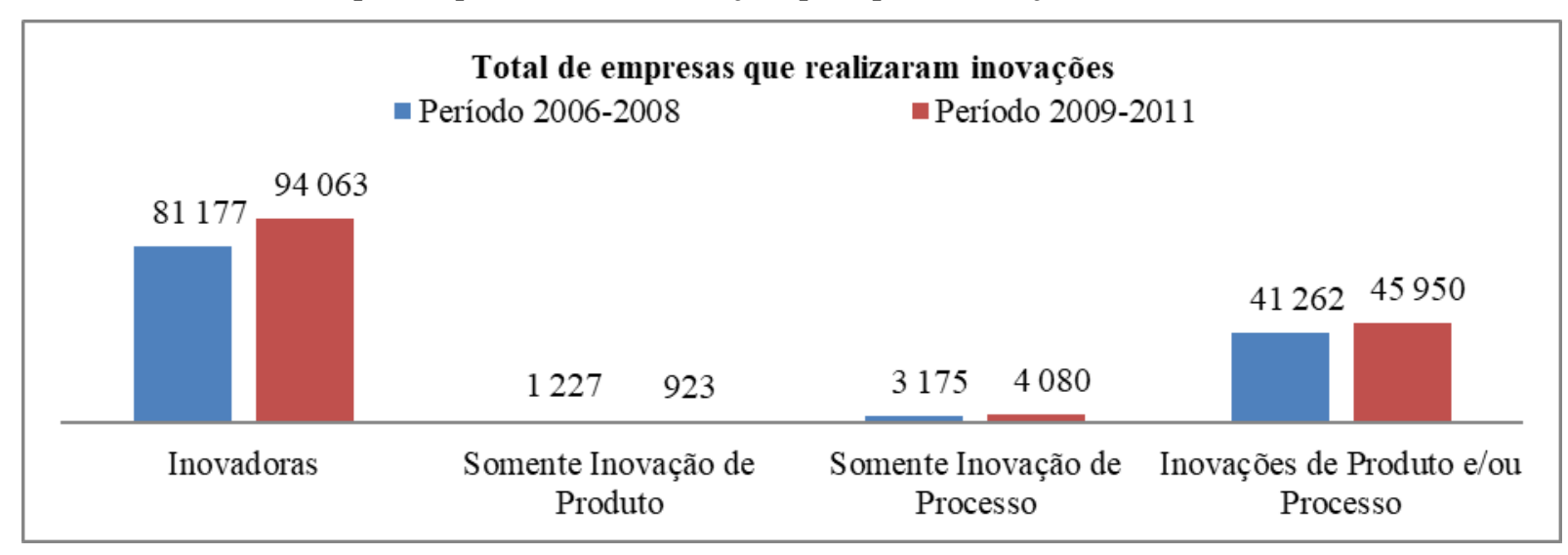

Fonte: Adaptado de IBGE, Diretoria de Pesquisas, Coordenação de Indústria, Pesquisa Industrial de Inovação Tecnológica 2008 e 2011.

Sugere-se que a preferência das empresas foi em realizar tanto inovações de produto como de processo concomitantemente, e não somente em um tipo de inovação especificamente. O Gráfico 2 apresenta a quantidade de empresas, por tipo de inovação realizada, e o impacto ("alto ou médio", "baixo ou não relevante") da inovação no "produto", especificamente na "ampliação da gama de produtos ofertados" e "melhoria na qualidade dos produtos".

Analisando-se o impacto da "ampliação da gama de produtos ofertados", por tipo de inovação realizada, destaca-se como de "alto ou médio" grau de importância o grupo de empresas que realizaram "somente inovação de produto" (79,2\% na edição de 2008 e 92,9\% na edição de 2011) e "inovação de produto e/ou processo" (61,9\% na edição de 2008 e 66,8\% na edição de 2011).

Portanto, considera-se que a "ampliação da gama de produtos ofertados" é um impacto considerado como de "alto ou médio" grau de importância, principalmente pelos grupos que realizaram concomitantemente "inovação de produto e/ou processo" (neste grupo, tanto em termos absolutos como relativos).

Acerca da "melhoria da qualidade dos produtos", considera-se que, em relação à quantidade de empresas inovadoras, 38,4\% relataram o impacto de grau "alto ou médio" na PINTEC edição de 2008, e 40\% na PINTEC na edição de 2011, um aumento de 20,9\% em relação à quantidade de empresas. Houve aumento no percentual de empresas, comparando-se os dois períodos, no grupo de empresas que realizaram "inovações de produto e processo" $(81,9 \%)$. Considera-se então que a "melhoria na qualidade dos produtos" é um impacto 
considerado como de "alto ou médio" grau de importância principalmente pelos grupos que realizaram concomitantemente "inovação de produto e/ou processo".

Gráfico 2 - Quantidade de empresas e o grau de impacto das inovações no produto.

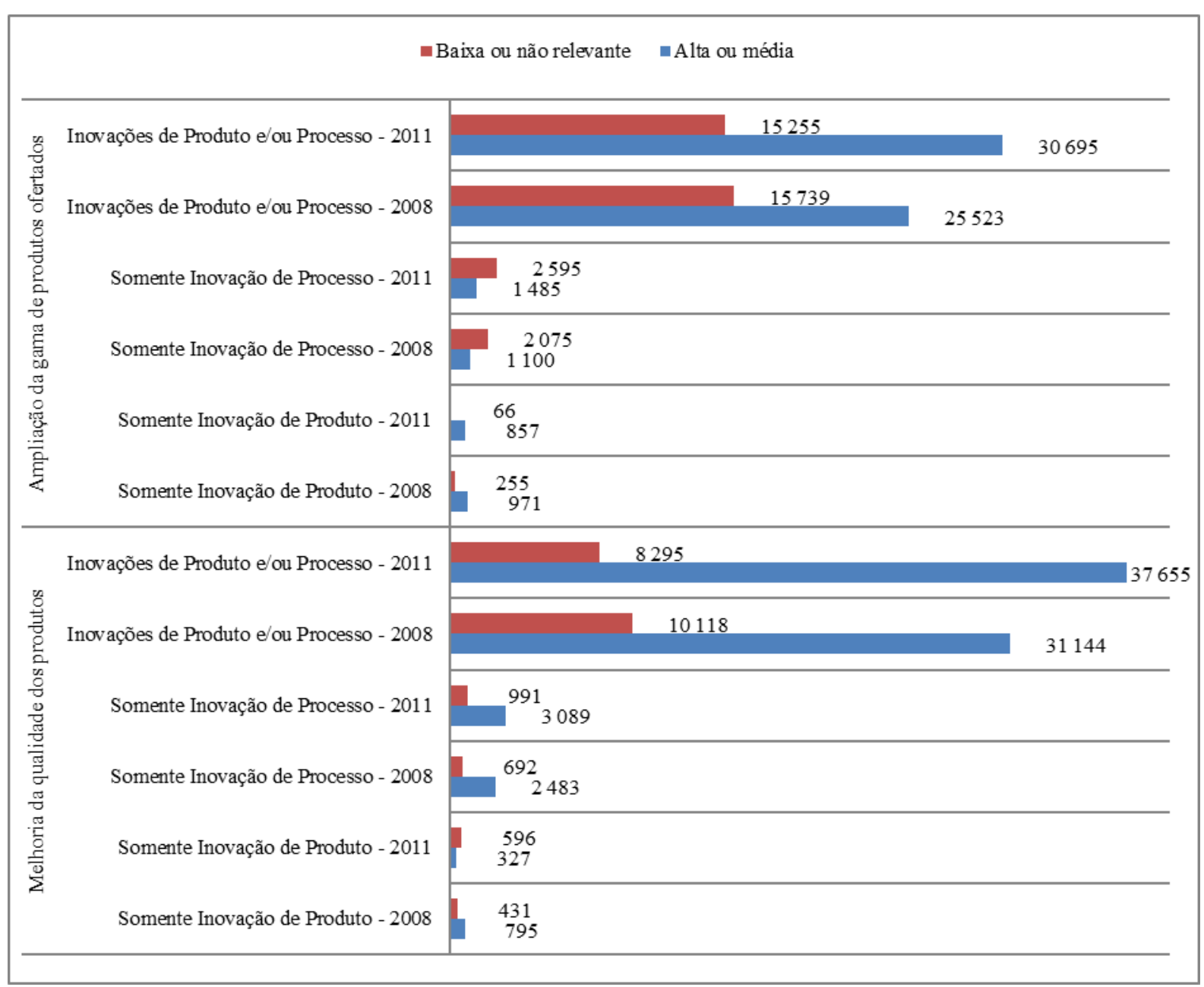

Fonte: Dados da pesquisa.

O Gráfico 3 apresenta a quantidade de empresas pelo grau de impacto no processo, em relação à flexibilidade da produção e da capacidade produtiva. $\mathrm{O}$ impacto causado pelo "aumento da flexibilidade da produção" é evidenciado nas empresas do grupo "inovações de produto e/ou processo", onde 73,2\% das empresas consideraram como de grau "alto ou médio" Isso mostra a relevância dada pelas empresas desse grupo para esse tipo de impacto.

A respeito do impacto no desempenho acerca do "aumento da capacidade produtiva", a quantidade de empresas do grupo "inovações de produto e/ou processo" que mencionaram como de grau "alto ou médio" na PINTEC de 2011 (75,8\%) foi superior 7,8 pontos percentuais ao da PINTEC de 2008. 
Gráfico 3 - Quantidade de empresas pelo grau de impacto no processo: flexibilidade da produção e capacidade produtiva.

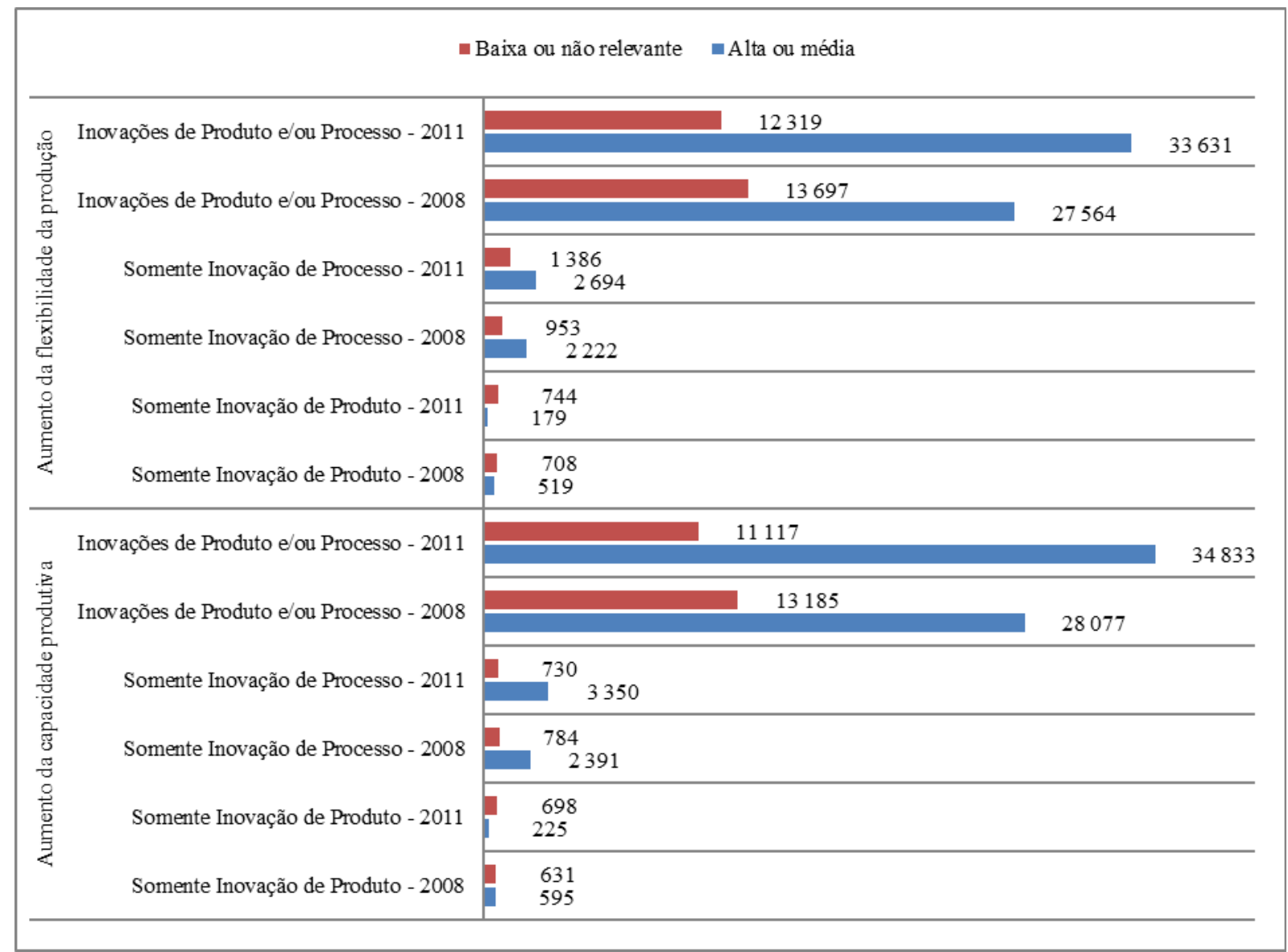

Fonte: Dados da pesquisa.

Considera-se então que o "aumento da flexibilidade da produção" e o "aumento da capacidade produtiva" importam para as empresas que realizaram inovações de produto e/ou processo. O Gráfico 4 apresenta a quantidade de empresas pelo grau de impacto no processo, especificamente acerca dos custos do trabalho e de produção.

Analisando-se o impacto causado na "redução dos custos do trabalho", identificou-se que $48,7 \%$ das empresas do grupo "inovação de produto e/ou processo" apontaram como de impacto "baixo ou não relevante", na edição de 2008, e de 47,2\% na edição de 2011; do total de empresas que realizaram "somente inovação de produto", 64,4\% (edição de 2008) e 93,9\% (edição de 2011) apontaram como de impacto "baixo ou não relevante". Também foi possível observar o aumento da quantidade de empresas que realizaram "inovação de produto e/ou processo", que apontaram como "alto ou médio" o grau de impacto da inovação comparandose as edições da PINTEC utilizadas no estudo. 
Gráfico 4 - Quantidade de empresas pelo grau de impacto no processo: custos do trabalho e de produção.

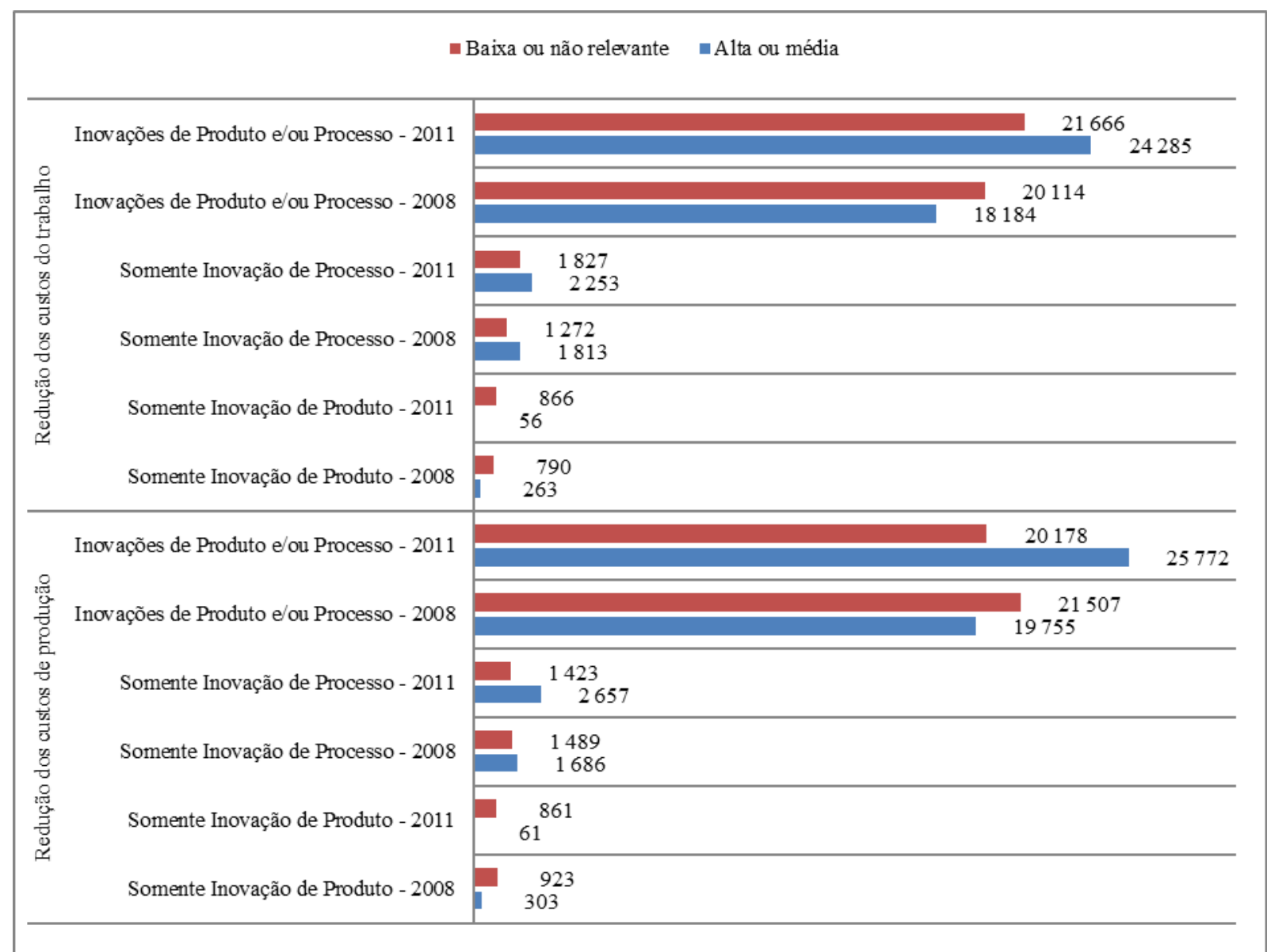

Fonte: Dados da pesquisa.

Em relação ao impacto "redução dos custos de produção", pode-se destacar que, do total das empresas do grupo "inovações de produto e/ou processo", 47,9\% (edição de 2008) apontaram como de grau "alto ou médio", mas este percentual foi de 56,1\% na edição de 2011 . Ainda em relação a este tipo de impacto, foi possível observar que, do total de empresas que realizaram "somente inovação de produto", o percentual de empresas que apontaram como de grau "baixo ou não relevante" foi de 75,3\% (edição de 2008), e de 93,4\% (edição de 2011). Também foi possível observar que, do total de empresas que realizou "somente inovação de processo", em relação à "redução dos custos de produção", houve um aumento de 12 pontos percentuais (53,1\% na edição de 2008 e 65,1\% na edição de 2011) nas empresas que apontaram como de grau "alto ou médio".

O Gráfico 5 apresenta a quantidade de empresas e o grau de impacto no processo, especificamente acerca da "redução do consumo de água", "redução do consumo de energia" e "redução do consumo de matéria-prima". A "redução do consumo de matéria-prima" foi considerada pela maioria das empresas de todos os grupos investigados como de impacto "baixo 
ou não relevante". Esse fator pode indicar que este tipo de impacto não proporciona, na maioria das empresas, influência no desempenho das empresas. Também pode significar que as empresas possuem certa evolução no uso da matéria-prima, e sua redução não é um fator principal, que provoque impacto considerável no desempenho.

Gráfico 5 - Quantidade de empresas pelo grau de impacto no processo: consumo de água, energia e matéria-prima.

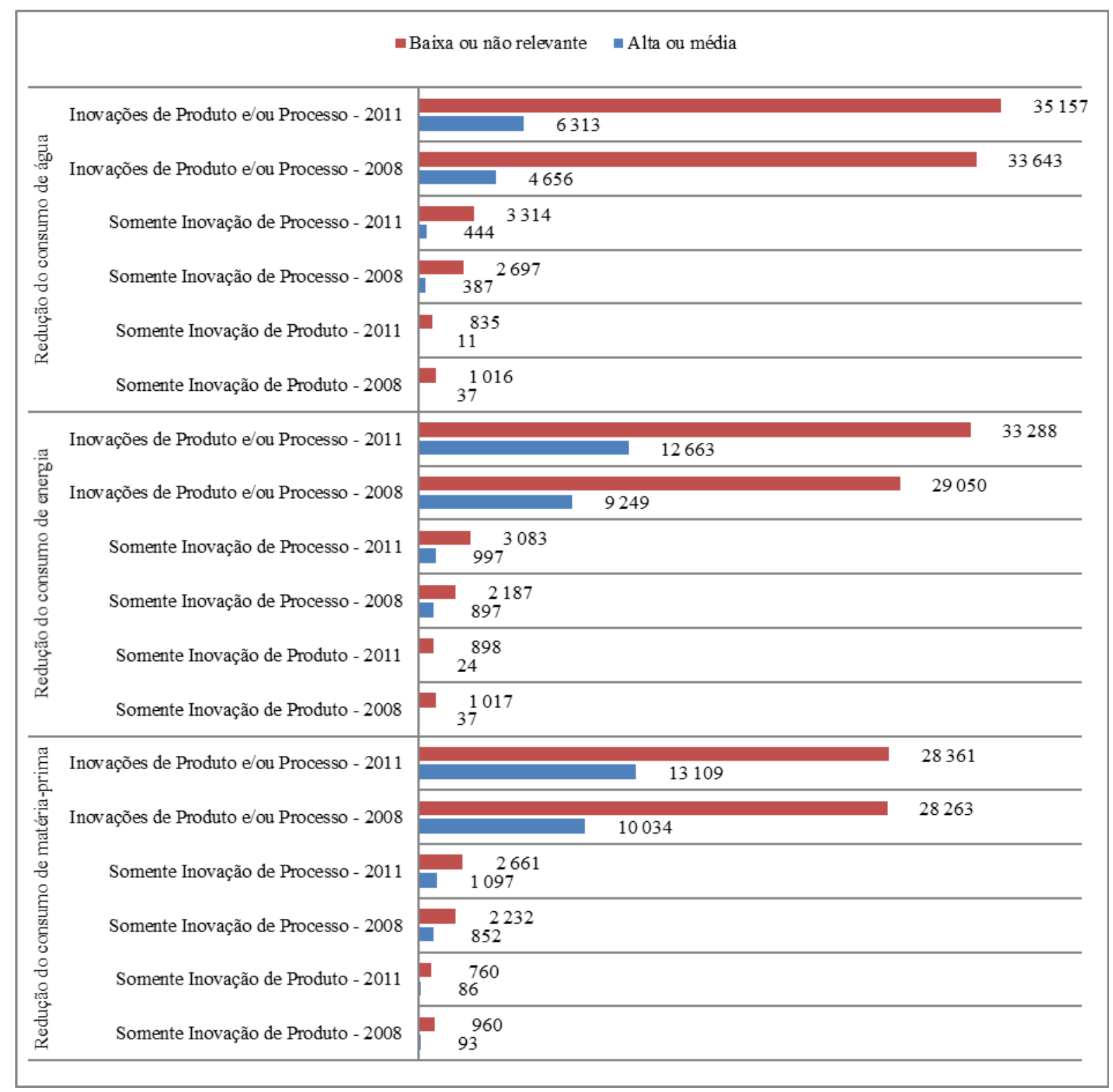

Fonte: Dados da pesquisa.

A "redução do consumo de energia" também foi considerada, pela maioria das empresas de todos os grupos investigados, como de impacto "baixo ou não relevante". Isso pode demonstrar que este tipo de impacto não proporciona, na maioria das empresas, influência relevante no desempenho das empresas. A "redução do consumo de energia", apesar de ser um item muito discutido atualmente no Brasil, não se mostrou um item de grau "alto ou médio"

P2P \& INOVAÇÃO, Rio de Janeiro, v. 7, n. 1, p. 260-274, set. 2020/fev. 2021. 
pelas empresas pesquisadas, o que pode demonstrar, nesse caso, que as empresas, apesar de considerarem importante, esta redução não representa impacto relevante no desempenho.

A "redução do consumo de água" foi considerada (da mesma forma que a redução de matéria-prima e energia) pela maioria das empresas de todos os grupos investigados como de impacto "baixo ou não relevante". Também pode significar que a "redução do consumo de água" não é um fator principal, que provoque impacto considerável no desempenho das empresas, porém, é uma preocupação crescente, pois o percentual de todos os grupos de empresas que mencionaram como de grau "alto ou médio" cresceu, e das que mencionaram como de grau "baixo e não relevante" diminuiu.

\section{CONSIDERAÇÕES FINAIS}

Considerando-se que o objetivo deste estudo foi verificar o grau de impacto das inovações de produto e processo nas indústrias situadas no Brasil, pode-se destacar alguns aspectos, com base nos resultados deste estudo.

A "redução dos custos de produção" é um impacto considerado como de grau "alto ou médio" principalmente pelas empresas que realizaram "inovação de processo". A "redução do consumo de água", a "redução do consumo de energia" e a "redução do consumo de matériaprima" foram consideradas de impacto "baixo ou não relevante", pela maioria das empresas, e que a "redução do consumo de água" é um dos impactos que apresentam como de menor preocupação pelas empresas pesquisadas.

Pode-se concluir, com base nos resultados deste estudo, que houve quantidade superior de empresas no grupo que realizaram mais de um tipo de inovação, em detrimento aos grupos que realizaram somente um tipo especificamente, demonstrando que os impactos causados nas inovações ocorreram principalmente nas empresas que realizaram mais de um tipo de inovação; as empresas industriais situadas no Brasil se importam principalmente com o impacto ("alto ou médio") da inovação "no produto" e "no mercado"; "no processo" elas se importam principalmente com o "aumento da flexibilização da produção" e "aumento da capacidade produtiva".

Algumas limitações foram encontradas para a realização da pesquisa. Uma delas está relacionada com os dados disponibilizados pelo IBGE, acerca das empresas que somente realizaram "inovação organizacional" e somente "inovação em marketing”, onde não foi possível, para esses grupos de empresas, obter dados dos impactos das inovações, pois essas empresas não respondem esta parte do questionário da PINTEC. 


\section{REFERÊNCIAS}

AGÊNCIA BRASILEIRA DE DESENVOLVIMENTO INDUSTRIAL. Contribuições para a política de desenvolvimento industrial, de inovação e de comércio exterior: período 2011/2014. Brasília, DF: ABDI, [2014?]. Disponível em: https://jacksondetoni.files.wordpres s.com/2012/05/texto-teorico-pbm.pdf. Acesso em: 20 ago 2020.

ARISS, S. S.; DEILAMI, V. S. An integrated framework for the study of organizational innovation. International Journal of Innovation Management, Singapore, v. 9, n. 1, p. 1-26, 2012.

BAREGHEH, A.; ROWLEY, J.; SAMBROOK, S. Towards a multidisciplinary definition of innovation. Management Decision, Melbourne, v. 47, n. 8, p. 1323-1339, 2009.

BAUMOL, W. J. The free-market innovation machine: analyzing the growth miracle of capitalism. Woodstock, Oxon: Princeton University Press, 2002.

BECKER, S. W.; WHISLER, T. L. The innovative organization: a selective review of current theory and research. The Journal of Business, Chicago, v. 40, n. 4, p. 462-469, 1967.

CHEN, J.; ZHAOHUI, Z.; XIE, H. Y. Measuring intellectual capital. Journal of Intellectual Capital, Singapore, v. 5, n. 1, p. 195-212, 2004.

CHRISTENSEN, C. M. The innovator's dilemma: when new technologies cause great firms to fail. Boston: Harvard Business Scholl Press, 1997.

DAMANPOUR, F. Organizational innovation: a meta-analysis of effect of determinants and moderators. Academy of Management Journal, New York, v. 34, n. 3, p. 555-590, 1991.

DAMANPOUR, F. Bureaucracy and innovation revisited: effects of contingency factors, industrial sectors, and innovation characteristics. Journal of High Technology Management Research, [S. l.], v. 7, n. 2, p. 149-173, 1996.

DOSI, G. Sourses, procedures and microeconomics effets of innovation. Journal of Economic Literature, Nashville, v. 26, 1988.

DOSI, G. Mudança técnica e transformação industrial: a teoria e uma aplicação à indústria dos semicondutores. Campinas: Editora Unicamp, 2006.

DOWNS Jr., G.; MOHR, L. Conceptual issues in the study of innovation. Administrative Science Quarterly, [S. l.], v. 21, n. 4, p. 700-714, 1976.

EVANGELISTA, R.; VEZZANI, A. The economic impact of technological and organizational innovations: a firm-level analysis. Research Policy, [S. l.], n. 39, 2010.

FREEMAN, C. The economics of industrial innovation. Cambridge: MIT Press, 1974.

GARCIA, R.; CALANTONE, R. A critical look at technological innovation typology and innovativeness terminology: a literature review. Journal of Product Innovation Management, [S. l.], v. 19, p. 110-132, 2001. 
GARCIA-MORALES, V. J.; MATIAS-RECHE, F.; HURTADO-TORRES, N. Influence of transformational leadership on organizational innovation and performance depending on the level of organizational learning in the pharmaceutical sector. Journal of Organizational Change Management, Melbourne, v. 21, n. 2, p. 188-212, 2008.

HENDERSON, R.; CLARK, K. Architectural innovation: the reconfiguration of existing product technologies and the failure of established firms. Adminstrative Science Quarterly, [S. l.], v. 35, p. 9-30, 1990.

INSTITUTO BRASILEIRO DE GEOGRAFIA E ESTATÍSTICA. Pesquisa de inovação: PINTEC 2008. Rio de Janeiro: IBGE, 2010.

INSTITUTO BRASILEIRO DE GEOGRAFIA E ESTATÍSTICA. Pesquisa de inovação: PINTEC 2011. Rio de Janeiro: IBGE, 2013.

KNIGHT, K. E. A descriptive model of intra-firm innovation process. Journal of Management, [S. l.], v. 41, n. 4, p. 478-496, 1967.

OCDE. Manual de Oslo: diretrizes para coleta e interpretação de dados sobre inovação. 3. ed. Rio de Janeiro: FINEP, 2005.

PLESSIS, M. D. The role of knowledge management in innovation. Journal of Knowledge Management, [S. l.], v. 11, n. 4, p. 20-29, 2007.

SCHUMPETER, J. A. Capitalismo, socialismo e democracia. Rio de Janeiro: Fundo de Cultura, 1961.

SCHUMPETER, J. A. Teoria do desenvolvimento econômico. São Paulo: Editora Abril Cultural, 1982.

THOMPSON, V. A. Bureaucracy and innovation. Administrative Science Quarterly, [S. l.], v. 10, p. $1-20,1965$.

TUSHMAN, M.; NADLER, D. Organizing for innovation. California Management Review, Berkeley, v. 28, n. 2, p. 74-92, 1986.

WEST, M. A.; ANDERSON, N. R. Innovation in top management teams. Journal of Applied Psychology, Washington, v. 81, p. 680-693, 1996. 